\title{
Situação de estudo e abordagem temática: análises sobre as escolhas dos temas
}

Josiane Marques da Silva josimarquesilva@gmail.com Universidade Federal de Santa Maria (UFSM), Santa Maria, Rio Grande do Sul, Brasil

Thiago Flores Magoga thiago.ufsm@gmail.com orcid.org/0000-0002-1532-1355 e Santa Maria (UFSM), Santa Maria, Rio Grande do Sul, Brasil

Cristiane Muenchen crismuenchen@yahoo.com.br orcid.org/0000-0003-3144-0933 Universidade Federal de Santa Maria (UFSM), Santa Maria, Rio Grande do Sul, Brasil

\section{RESUMO}

Neste estudo são discutidos os processos de escolhas de temas no contexto das perspectivas de reorganização curricular da Abordagem Temática e da Situação de Estudo, por meio de uma revisão bibliográfica em trabalhos publicados nas atas do Encontro Nacional de Pesquisas em Educação em Ciências (ENPEC), no período de 1997 até 2017. Desta forma, este trabalho preocupa-se em responder o seguinte questionamento: Como os temas vêm sendo definidos em práticas educativas baseadas na Situação de Estudo, em comparação à Abordagem Temática? Metodologicamente de cunho qualitativo, a análise dos trabalhos selecionados foi orientada pelos pressupostos da Análise Textual Discursiva emergindo, assim, duas categorias analíticas (i) Vivências cotidianas como balizadoras das escolhas e ii) Distintos parâmetros de escolhas. Sinaliza-se, com isso, a aparente distinção nas interpretações dos elementos da tríade sujeito - contexto - conhecimento científico para a escolhas e abordagem dos temas no âmbito das perspectivas curriculares Situação de Estudo e Abordagem Temática.

PALAVRAS-CHAVE: Escolha dos Temas. Perspectivas curriculares. Situação de Estudo. Abordagem Temática. Práticas Educativas. 


\section{INTRODUÇÃO}

Discussões em torno de questões vinculadas aos currículos escolares têm ganhado amplitude nas últimas décadas, com a publicação dos Parâmetros Curriculares Nacionais (PCN) nos anos 90, e com a recente adoção da Base Nacional Comum Curricular (BNCC) (BRASIL, 2018). Tais discussões voltaram-se para aspectos estruturantes dos currículos e, desta forma, no âmbito do Ensino de Ciências, diversos estudos têm abordado a necessidade de (re)pensar os currículos de ciências.

Neste contexto, se insere a Abordagem Temática (AT) (DELIZOICOV, ANGOTTI, PERNAMBUCO, 2011) e a Situação de Estudo (SE) (MALDANER, 2007) como perspectivas, que em sua gênesis, objetivam a reorganização de currículos escolares por meio de temas. A AT propõe um outro olhar sobre o que se entende por currículo escolar, de modo que Marques et al. (no prelo) defendem a necessidade dos currículos escolares não serem pautados na repetição de conteúdos. Neste sentido, para a superação do modelo curricular conceitual a AT busca romper "[...] com a lógica segundo o qual os programas têm sido elaborados, a saber: a estruturação pela abordagem conceitual, que organiza os conteúdos escolares com base em um elenco de conceitos científicos" (DELIZOICOV, ANGOTTI, PERNAMBUCO, 2011, p. 272).

A partir desta concepção de superação da lógica conceitual, a AT vai além de métodos a serem trabalhados, já que propõe uma reorganização dos Currículos de Ciências. Conforme Hunsche (2010), existem na literatura da área de Educação em Ciências distintas propostas curriculares fundamentadas por temas, a exemplo da Abordagem Temática Freireana (ATF) (DELIZOICOV, ANGOTTI, PERNAMBUCO, 2011), inspirada pelos pressupostos Freireanos; a Educação em Ciência, Tecnologia e Sociedade (CTS) (STRIEDER, 2012) tem a finalidade de inserir nos currículos questões vinculadas à temas sociocientíficos; a articulação do referencial Freireano com a Educação CTS (Freire-CTS) (AULER, 2002); e a Situação de Estudo (MALDANER, 2007) pedagogicamente fundamentada pela teoria da abordagem histórico-cultural de Lev Semionovitch Vigotski.

Ancorada pelo referencial Vigotskiano, a SE compreende por meio da significação conceitual que aspectos do cotidiano do estudante devem estar relacionados com a abordagem dos conteúdos escolares. Deste modo, entende-se que a escolha dos temas que fundamentam o currículo em cada uma destas perspectivas - SE e AT - pode ser diferente, pois tal obtenção deve estar atrelada aos pressupostos pedagógicos das propostas curriculares, ou seja, da forma que concebem e executam os currículos. Nessa perspectiva, se insere este trabalho o qual está ancorado na seguinte questão de pesquisa: Como os temas vêm sendo definidos em práticas educativas baseadas na Situação de Estudo, em comparação à Abordagem Temática? Para responder esta pergunta realizou-se processos de revisão e análise, os quais serão descritos nas próximas seções.

\section{APONTAMENTOS TEÓRICOS-METODOLÓGICOS}

Os processos de obtenção de temas em perspectivas que visam a reorganização curricular são orientados de acordo com seus referenciais pedagógicos. Halmenschlager (2014) discute e caracteriza as perspectivas da AT 
com diferentes enfoques temáticos, conforme a natureza de obtenção dos temas, classificadas como Propostas de Reorganização Curricular Conceitual e/ou Propostas de Organização Curricular Contextual. As propostas de cunho conceitual são originadas por temas fundamentados nos conceitos das ciências e as abordagens contextuais são oriundas de propostas que concebem os temas a partir do contexto dos estudantes, podendo contemplar as dimensões sociais, políticas, econômicas, ambientais, entre outras.

Deste modo, se entende que a maneira às quais os temas são concebidos nas proposições da AT podem estar relacionados à tríade - sujeitos - contexto conhecimento científico, assim, como cada perspectiva curricular possui maneiras próprias de obter os temas, as relações entre a tríade podem ser singulares, por exemplo, o contexto na ATF é algo a ser problematizado e transformado, na Educação CTS almeja-se uma transformação, mas esta está muito arraigada às relações entre ciência e tecnologia. Vale destacar, que os sujeitos podem ser estudantes, professores e comunidades escolar e local, já contexto pode ser entendido como realidade, ou seja, algo a ser transformado.

No âmbito da ATF o contexto é o ponto de partida para a obtenção do tema, com isso o tema nesta perspectiva é chamado de Tema Gerador, por tratar de releituras da epistemologia freireana. Muenchen et al. (2019) salientam que a chegada ao Tema Gerador pode ser conduzida por meio de processos, quais sejam: Investigação Temática (IT) (DELIZOICOV, 1991), Três Momentos Pedagógicos como Estruturantes de Currículo (3MP) (MUENCHEN, 2010), e Práxis Curricular via Tema Gerador (Momentos) (SILVA, 2004). Assim, na ATF os sujeitos são a comunidade escolar em um processo coletivo, dialógico e problematizador de chegada ao Tema Gerador, partindo do contexto em que os conhecimentos científicos são subordinados ao Tema Gerador, servindo como meios de compreensão deste.

Tendo em vista à Educação CTS, as relações entre os elementos da tríade parecem exercer protagonismos distintos em comparação à ATF. Os temas na Educação CTS são concebidos de forma contextual e/ou conceitual, assim, percebe-se que o conhecimento científico pode fazer parte da obtenção do tema e não somente na abordagem do tema como na ATF. Os temas no interior da Educação CTS são originados por contextos que envolvem a realidade regional, nacional, mundial ou assuntos em repercussão midiática (HUNSCHE, 2010), podendo ser selecionados pelo professor, característica distinta da ATF em que o professor também assume o papel de protagonista na construção dos currículo, mas o contexto é bem explicitado sendo a realidade da comunidade escolar.

A fusão da ATF e Educação CTS, são defendidas por Auler, Dalmolin e Fenalti (2009) na denominada articulação Freire-CTS, a qual a relação dos elementos da tríade nesta perspectiva são tangenciadas, em que os sujeitos - contexto conhecimento científicos passam a possuir a mesma dimensão que na ATF, bem como, a finalidade desta articulação está atrelada a conscientização e transformação do contexto por meio da participação social em discussões relacionadas à Ciência e Tecnologia e percepção da Ciência como construção humana e não neutra.

A obtenção dos temas na SE "obedecem" a relação de uma outra tríade, sendo ela formadores - licenciandos - professores da Educação Básica, e é neste ambiente coletivo que são elaboradas as SE (VIEIRA, 2017). Assim, as relações 
sujeito - contexto - conhecimento científico, tomam outra dimensão, em que os temas são obtidos através do contexto, percebido como vivencial/cotidiano e/ou a partir dos conhecimentos científicos (MAGOGA, SILVA, MUENCHEN, 2020). Assim como na ATF e na articulação Freire-CTS, os conhecimentos científicos na SE possuem sentido de finalidade na reorganização do currículo escolar, uma vez que, na ATF e Freire-CTS destina-se a transformação e conscientização e na SE, pautada nos pressupostos Vigotskiano, visa a significação conceitual.

Baseando-se na necessidade de aprofundar tais discussões, o que possibilitaria evidenciar a importância mas também singularidades de ambas as perspectivas curriculares (SE e AT), o presente estudo, de natureza qualitativa, trata-se de uma revisão bibliográfica (GIL, 2010) nas atas do Encontro Nacional Pesquisa em Educação em Ciências (ENPEC), onde através de um recorte temporal de vinte anos, foram analisados 6119 trabalhos publicados nas onze edições deste evento, no período de 1997 até 2017 1'.

A revisão bibliográfica apresentada neste trabalho parte de sinalizações discutidas em estudo anterior (MAGOGA, SILVA, MUENCHEN, 2020) em que foram apresentadas aproximações e distanciamentos entre a perspectiva da Situação de Estudo e a Abordagem Temática. Como ambas são perspectivas de reorientação curricular fundamentadas por temas, assim, emergiu a necessidade de compreender os processos de obtenção de temas no âmbito da SE em relação às proposições existentes na literatura do Ensino de Ciências sobre a obtenção de temas na AT.

O método analítico da amostra de trabalhos foi conduzido por fichamento (GIL, 2010), que consiste em um sistema de organização das ideias com vista a atender aos objetivos delineados no início da pesquisa. Assim, foi realizada a leitura na íntegra dos trinta e cinco trabalhos selecionados, com objetivo de identificar trabalhos práticos, pois são estes que abordam temas das SE e tendem a discutir os modos de obtenção e abordagem. A partir desta análise, identificouse vinte e dois trabalhos práticos.

Quadro 1 - Características do corpus

\begin{tabular}{|c|c|c|c|}
\hline Id. & Ano & Título & SE \\
\hline 1 & 2001 & $\begin{array}{l}\text { Situação de Estudo como possibilidade } \\
\text { concreta de ações coletivas } \\
\text { interdisciplinares no ensino médio - Ar } \\
\text { Atmosférico - }\end{array}$ & Ar Atmosférico \\
\hline 2 & 2003 & $\begin{array}{l}\text { A inserção do debate epistemológico no } \\
\text { âmbito da educação em ciências }\end{array}$ & Ar Atmosférico \\
\hline 3 & 2005 & $\begin{array}{l}\text { Significação dos Conceitos de Ciências } \\
\text { Naturais e suas Tecnologias numa } \\
\text { Perspectiva Interdisciplinar: análise de } \\
\text { uma Situação de Estudo }\end{array}$ & $\begin{array}{l}\text { Alimentos: Produção e } \\
\text { Consumo }\end{array}$ \\
\hline 4 & & $\begin{array}{c}\text { Contextualização e Significação no } \\
\text { Ensino de Ciências Naturais }\end{array}$ & $\begin{array}{l}\text { Como o ser humano percebe e } \\
\text { interage com o ambiente }\end{array}$ \\
\hline
\end{tabular}




\begin{tabular}{|c|c|c|c|}
\hline Id. & Ano & Título & SE \\
\hline 5 & & $\begin{array}{c}\text { Compreensão das Ciências Naturais } \\
\text { como Área de Conhecimento no Ensino } \\
\text { Médio - Conceitos Unificadores }\end{array}$ & $\begin{array}{l}\text { De Alguma Forma Tudo se } \\
\text { Move }\end{array}$ \\
\hline 6 & \multirow{4}{*}{2009} & $\begin{array}{c}\text { Currículo por Área de Conhecimento no } \\
\text { Ensino Médio: possibilidades criadas } \\
\text { com situações de estudo nas ciências da } \\
\text { natureza }\end{array}$ & $\begin{array}{l}\text { Interconversões de energia em } \\
\text { processos biofisicoquímicos }\end{array}$ \\
\hline 7 & & $\begin{array}{c}\text { A Presença da Divulgação Científica no } \\
\text { Processo de Ensino-Aprendizagem do } \\
\text { Nível Médio }\end{array}$ & Aquecimento Global do Planeta \\
\hline 8 & & $\begin{array}{c}\text { Ações de Estagiárias da Licenciatura em } \\
\text { Química em Proposta de Inovação } \\
\text { Curricular }\end{array}$ & $\begin{array}{l}\text { Os medicamentos e as dores } \\
\text { dos seres humanos: síntese e } \\
\text { ação de fármacos }\end{array}$ \\
\hline 9 & & $\begin{array}{l}\text { Drogas: uma proposta de organização } \\
\text { curricular que articula formação } \\
\text { docente }\end{array}$ & $\begin{array}{c}\text { Drogas - efeitos e } \\
\text { conseqüências no ser humano }\end{array}$ \\
\hline 10 & \multirow{4}{*}{2011} & $\begin{array}{l}\text { Problematização no ensino de Ciências: } \\
\text { Uma Análise da Situação de Estudo }\end{array}$ & $\begin{array}{l}\text { Ar Atmosférico, Água e Vida e } \\
\text { De alguma forma tudo se } \\
\text { move; No escuro todos os } \\
\text { gatos são pardos e } \\
\text { Interconversões de matéria e } \\
\text { energia nos aspectos biofísicos, } \\
\text { biológicos e tecnológicos }\end{array}$ \\
\hline 11 & & $\begin{array}{c}\text { Especificidade no Desenvolvimento de } \\
\text { Situação de Estudo: Perguntas do } \\
\text { Professor }\end{array}$ & Água e Vida \\
\hline 12 & & $\begin{array}{c}\text { Condições de Produção do } \\
\text { Conhecimento Escolar: Uma 'Situação } \\
\text { de Estudo' em Foco }\end{array}$ & $\begin{array}{c}\text { Ribeirão entre córregos (Tema: } \\
\text { Água) }\end{array}$ \\
\hline 13 & & $\begin{array}{l}\text { Problematização na Produção da } \\
\text { Situação de Estudo "Aquecimento } \\
\text { Global" numa Escola de Ensino Médio }\end{array}$ & $\begin{array}{l}\text { Aquecimento Global do Planeta } \\
\text { (nomeado posteriormente de } \\
\text { Ar atmosférico) }\end{array}$ \\
\hline 14 & \multirow{3}{*}{2013} & $\begin{array}{c}\text { Automedicação: Um mal necessário? } \\
\text { Uma Situação de Estudo Realizada pelo } \\
\text { PIBID/Química-UESC }\end{array}$ & $\begin{array}{c}\text { Automedicação: um mal } \\
\text { necessário? }\end{array}$ \\
\hline 15 & & $\begin{array}{c}\text { A Pesquisa como Instrumento } \\
\text { Metodológico no Processo de Ensino } \\
\text { Aprendizagem }\end{array}$ & $\begin{array}{l}\text { Alimentos como forma de } \\
\text { manutenção da vida }\end{array}$ \\
\hline 16 & & $\begin{array}{c}\text { PIBID/ Química UESC - Ensinando } \\
\text { concentração através de uma Situação } \\
\text { de Estudo no curso técnico de } \\
\text { Biotecnologia }\end{array}$ & $\begin{array}{l}\text { Alisantes - uma forma de } \\
\text { ensinar concentração }\end{array}$ \\
\hline
\end{tabular}




\begin{tabular}{|c|c|c|c|}
\hline Id. & Ano & Título & SE \\
\hline 17 & \multirow{3}{*}{2015} & $\begin{array}{l}\text { Contribuições da Situação de Estudo ao } \\
\text { processo formativo de futuros } \\
\text { professores de Química }\end{array}$ & Produtos de limpeza (Tema) \\
\hline 18 & & $\begin{array}{c}\text { Concepções de estudantes do ensino } \\
\text { médio sobre Radioatividade }\end{array}$ & $\begin{array}{l}\text { Radioatividade: quem disse } \\
\text { que só faz mal? (Tema: } \\
\text { Radioatividade) }\end{array}$ \\
\hline 19 & & $\begin{array}{l}\text { O Ensino-aprendizagem em Ciências } \\
\text { com base no tema gerador combustível } \\
\text { fóssil x biocombustível }\end{array}$ & $\begin{array}{l}\text { Combustível fóssil x } \\
\text { biocombustível (Tema) }\end{array}$ \\
\hline 20 & \multirow{3}{*}{2017} & $\begin{array}{l}\text { A autoria coletiva na produção de } \\
\text { Currículo Interdisciplinar: um processo } \\
\text { de formação de professores }\end{array}$ & $\begin{array}{l}\text { Violência; Saúde Pública; } \\
\text { Violência e Saúde Pública } \\
\text { (Temáticas da SE) }\end{array}$ \\
\hline 21 & & $\begin{array}{l}\text { A interdisciplinaridade como ação } \\
\text { potencializadora no desenvolvimento } \\
\text { de professores de ciências }\end{array}$ & $\begin{array}{l}\text { Biocombustível como fonte } \\
\text { alternativa de energia: relações } \\
\text { entre ciência, tecnologia, } \\
\text { cultura e trabalho no ambiente }\end{array}$ \\
\hline 22 & & $\begin{array}{l}\text { Preparando um café no laboratório de } \\
\text { química: investigação de uma } \\
\text { abordagem para conceitos de Química } \\
\text { através do desenvolvimento de uma } \\
\text { Situação de Estudo com o tema café }\end{array}$ & Café (Tema) \\
\hline
\end{tabular}

Fonte: Autoria própria (2019).

A análise destes últimos, também foi orientada pelo método de fichamento, na perspectiva de caracterizar o processo de obtenção de temas nas SEs. Os dados obtidos por meio do referido método foram sistematizados através da Análise Textual Discursiva (MORAES; GALIAZZI, 2007), organizada em três etapas de análise: (1) Unitarização: caracterizada pela desconstrução dos textos em que os dados são separados pelo pesquisador por unidades de significados; (2) Categorização: etapa em que emergem as categorias de análise, através do agrupamento de elementos semelhantes dos dados da pesquisa; e (3) Comunicação: etapa que consiste na produção textual em forma de metatextos. A partir deste processo, as unidades de significados foram identificadas pelo sistema alfanumérico: identificação do trabalho_número da unidade, por exemplo, T1_1 (unidade de significado 1 retirada do trabalho 1 ).

Sinaliza-se que as discussões apresentadas neste estudo foram construídas a partir de resultados analíticos da amostra de trabalhos encontrados por meio da revisão bibliográfica, assim, os processos de obtenção dos temas na SE serão discutidos de forma articulada com os pressupostos da AT. Reitera-se que não se tem a intenção de mensurar valores das referidas perspectivas, mas de analisar o(s) processo(s) de obtenção de temas na SE articulando com o que já está expresso na literatura sobre obtenção de temas no contexto da AT. Assim, serão delineadas semelhanças e particularidades entre ambas. 
Tendo em vista o propósito de discutir os elementos considerados para a escolha dos temas, a análise do corpus permitiu o delineamento de duas categorias emergentes: i) vivências cotidianas como balizadoras das escolhas; e ii) distintos parâmetros de escolhas. As discussões sobre cada categoria e as possíveis relações com a AT são realizadas na sequência.

\section{ANÁLISES E DISCUSSÕES}

O primeiro importante destaque acerca das análises está associado ao fato das denominações utilizadas nos vinte e dois trabalhos, referentes às temáticas desenvolvidas, isto é, ao modo como se referem ao assunto/problema/trama que organizou o planejamento e currículo escolar. Apesar de todos os trabalhos abordarem a perspectiva curricular SE, durante a ação prática alguns autores denominaram a trama desenvolvida ora como tema, ora como SE.

Observou-se, por exemplo, que nos trabalhos 12, 17, 18, 19, 20 e 22, desenvolvem-se temas/temáticas na perspectiva da SE. No restante dos artigos, os autores utilizam, de maneira mais sistemática, a expressão "Situação de Estudo" para indicar a obtenção e aplicação do planejamento estruturado. Como exemplos do uso destas expressões, apresentam-se as unidades abaixo:

O desenvolvimento de uma SE em uma situação real de sala de aula no ensino básico, grau médio, foi outro contexto de investigação. Através de gravações de aulas da SE Ar Atmosférico, desenvolvida na [escola] [...]. O desenvolvimento dessa SE foi possível com a colaboração decisiva da [escola] [...] (T2_2).

Depois das primeiras reuniões na escola logo decidimos que o tema de estudo seria "Água", no contexto da cidade, [...] Este tema da SE foi abordado em disciplinas de Química, Geografia e Biologia, sobre diferentes perspectivas e com diferentes conteúdos (T12_1).

A partir da unidade T2_2, percebe-se que o Ar atmosférico assunto/tópico/trama trabalhado - é apresentado como a SE, ou seja, está baseado na perspectiva da SE e é a própria situação. Já na unidade representativa T12_1, os autores utilizam-se da perspectiva curricular da SE para, a partir desta, trabalhar o tema "Água", ou seja, inferindo a análise de que o assunto/tópico/trama é um tema o qual se baseia na perspectiva da SE. Parece haver, portanto, diferenças entre afirmar que um planejamento é uma perspectiva curricular ou que está baseado em uma, mas organizado em torno de temas.

De modo geral, estas duas representações são observadas nos outros trabalhos do Quadro 1 e podem estar associadas a distintas premissas. Admite-se ser temerário aferir significados sobre o que causa essa distinta percepção e possíveis replicações - apesar de ser fundamental - até porque, tal diferenciação talvez não seja vista como uma questão importante de ser debatida, mesmo que do ponto de vista curricular e epistemológico seja. Entretanto, algumas considerações podem ser supostas ao se equiparar a SE à outra perspectiva curricular, como a AT.

Mesmo que não se tenha um estudo formal sobre tais aspectos, percebe-se que os trabalhos que utilizam AT, usualmente, estruturam e desenvolvem planejamentos organizados em torno de um tema, deixando claro tal asserção. Ao 
considerar, por exemplo, o corpus de análise de Klein et al. (no prelo), o qual discute justamente os temas na perspectiva curricular da AT, percebe-se que esta abordagem prescinde daqueles:

\begin{abstract}
Uma opção para criar atividades com uma conexão entre a sala de aula e o mundo é a utilização de práticas que façam uso de uma Abordagem Temática (AT), ou seja, uma abordagem em que se utilize temas que se encontram no cotidiano dos estudantes para ensinar-aprender os conteúdos escolares (FT29_C1_U1) (grifo nosso).

[...] é a importância de se trabalhar a ciência e a tecnologia a partir de temas que possuam grande relevância social, mostrando ao aluno o papel significativo do mesmo na sociedade. Alguns critérios são importantes no momento da seleção de um tema social para o currículo [...] (QT9_C1_U1) (grifo nosso).
\end{abstract}

Ressalta-se que em ambos os trabalhos, aos quais se referem às unidades, discute-se a organização curricular por meio da AT. Entretanto, torna-se imprescindível comentar que, diferentemente da SE, a perspectiva da AT possui certa definição disseminada por autores da área de Ensino de Ciências. De acordo com Magoga, Silva e Muenchen (2020), admite-se que as palavras de Delizoicov, Angotti e Pernambuco (2011, p.189), são fundamentais para entender a "perspectiva curricular cuja lógica de organização é estruturada com base em temas, com os quais são selecionados os conteúdos de ensino das disciplinas. Nessa abordagem, a conceituação científica da programação é subordinada ao tema". Amparando-se nessas palavras, portanto, fica evidente a relação entre a abordagem e o tema, e de como esta pode ter disseminado a proposta.

Distante de minimizar discussões, mas almejando auxiliar na proposição de tais, incita-se a pensar no fato de que na perspectiva da AT, epistemologicamente, é perceptível a necessidade de se nomear um tema para a estruturação dos planejamentos, e que estes (temas e planejamentos) compõem a abordagem temática. Todavia, na perspectiva da SE esta relação talvez esteja sendo epistemologicamente consolidada, pois se observa, por exemplo, que os trabalhos mais recentes do Quadro 1 são os que apresentam "temas da SE", diferindo dos mais antigos.

Mesmo que haja a necessidade de pesquisas de cunho epistemológico sobre estes aspectos, no presente trabalho as discussões avançaram considerando que, nos artigos do corpus, tema e SE são equivalentes, tendo em vista o objetivo de analisar os modos de obtenção/escolha destes. Portanto, nas palavras que seguem, tema e SE são sinônimos, e o foco é observar como as definições ocorrem, abordando paralelamente à AT. Faz-se isso com a intenção de elucidar que são perspectivas distintas, independentes, mas que possuem o mesmo grau de relevância.

Ao considerar a premissa do parágrafo anterior e ao analisar o Quadro 1, identifica-se a recorrência de títulos para os temas/SE dos artigos analisados. 
Quadro 2-Títulos dos Temas

\begin{tabular}{|c|c|}
\hline \multicolumn{1}{|c|}{ Temas } & $\begin{array}{c}\text { Trabalhos em } \\
\text { que aparecem }\end{array}$ \\
\hline Água e Vida & 10 e 11 \\
\hline Aquecimento global do planeta & 7 e 13 \\
\hline Ar atmosférico & $1,2,10$ \\
\hline De alguma forma tudo se move & 5 e 10 \\
\hline $\begin{array}{c}\text { Interconversões de energia em processos biofisicoquímicos/ } \\
\text { Interconversões de matéria e energia nos aspectos biofísicos, } \\
\text { biológicos e tecnológicos }\end{array}$ & 6 e 10 \\
\hline
\end{tabular}

Fonte: Autoria própria (2019).

Com base na leitura do Quadro 2 - Títulos dos Temas, identifica-se o uso de vinte e dois temas, nos desenvolvimentos das ações descritas nos artigos dos corpus. Este número, equivalente ao número de trabalhos analisados, dá-se pelo fato de que em alguns houve o desenvolvimento de mais de um tema (vide Quadro 1), mas também porque em distintos trabalhos, o tema se repetiu (vide Quadro 2).

A apresentação dos temas se torna importante pois auxilia nas reflexões acerca das práticas educativas, mas a identificação destes temas, por si só, não possibilita aferir respostas para a questão de pesquisa. Por isso mesmo, durante a leitura dos vinte e dois trabalhos, buscaram-se unidades de significado que, agrupadas, possibilitaram debates mais profundos.

Neste momento torna-se importante sinalizar que mesmo com repetidas leituras realizadas por pares de sujeitos, não foi possível identificar os modos de escolha/obtenção dos temas em todos os artigos do Quadro 1. Apesar de todos desenvolverem ações com a perspectiva curricular da SE, os trabalhos 1, 2, 3, 5, e 6 não explicitaram o processo de determinação do tema - de modo que fosse possível identificar -, apenas o seu desenvolvimento. Por isso mesmo, para a discussão das categorias não se utilizou unidades de significados oriundas daqueles.

Em relação aos demais, percebeu-se proximidades entre alguns fatos, como por exemplo, a importância do contexto vivencial dos alunos, da influência dos meios de comunicação, dos contextos de formação e suas estruturas préestabelecidas. Tais elementos compuseram e são discutidos nas categorias i) vivências cotidianas como balizadoras das escolhas; e ii) distintos parâmetros de escolha, na sequência. 


\section{VIVÊNCIAS COTIDIANAS COMO BALIZADORAS DAS ESCOLHAS}

A produção de uma SE inicia pela identificação de uma situação real (complexa, dinâmica e plural) e conceitualmente rica, percebida nos contextos de vivência cotidiana dos alunos fora da escola, sobre a qual eles têm o que dizer e em cujos contextos eles sejam capazes de produzir novos saberes, expressando-lhes significados e defendendo seus pontos (T21_1).

A unidade de significado acima é representativa da categoria como um todo, pois além do destaque ao contexto de vivência cotidiana, aborda, teoricamente, uma característica muito importante dentro da perspectiva curricular da SE: a íntima relação que este contexto possui com os conhecimentos científicos, desenvolvida por meio da significação conceitual.

As características marcadas pela unidade T21_1, portanto, se assemelham com outras identificadas nos trabalhos $4,9,10,11,12,17,19,20,21$ e 22 , os quais formam esta categoria. De modo geral, nestes arquivos, os temas foram definidos levando em consideração e/ou por meio de justificativas as quais giravam em torno da importância do contexto - da realidade; do cotidiano; das vivências dos estudantes - à qual a ação educativa se destinava, variando em um espectro deste uma experiência mais próxima/singular - como no trabalho 12, colocado anteriormente, em que o tema "Água" estava associado especificamente ao contexto da cidade de Ribeirão Preto -, a exemplos do cotidiano que podem ser ampliados a distintos contextos, como é o caso do trabalho 22 em que o tema "Café" foi desenvolvido pois se trata de uma bebida muito consumida em todo o mundo, fazendo parte do cotidiano.

Além de reunir trabalhos por meio da variação espectral citada acima, a composição desta categoria permitiu perceber dois aspectos referentes à definição das temáticas: i) são precisamente as práticas/experiências cotidianas (mesmo que haja variações da ideia de cotidiano) as quais justificam as escolhas e, também; ii) os alunos sugerem/escolhem as temáticas a serem desenvolvidas. Exemplos destas percepções i) e ii), são colocadas, respectivamente, abaixo:

\footnotetext{
Essa idéia [trazer o contexto através da interação entre disciplinas] esteve presente no desenvolvimento da SE: "Como o ser Humano Percebe e Interage com o Ambiente", que de uma forma interdisciplinar abordou conhecimentos sobre os cinco órgãos dos sentidos, relacionando e valorizando as interações das pessoas com o ambiente em que vivem, e geralmente não contempladas na 7ạ série do Ensino Fundamental (T4_1) (grifo nosso).
}

Cabe destacar que a escolha da SE: Drogas - efeitos e conseqüências no ser humano, na segunda série do ensino médio, foi sugerida pelos estudantes do ensino médio após terem vivenciado intensamente (na primeira série do Ensino Médio) o desenvolvimento da SE: Conhecendo o Câncer- um caminho para a vida [...]. Salientamos que os alunos manifestaram interesse na continuidade das aulas na forma de SE, argumentando que os conteúdos escolares se tornam muito mais interessantes, pois, "dá mais vontade de estudar quando se trata de algum assunto relacionado com o nosso dia a dia" (T9_2) (grifo nosso).

As justificativas presentes no trabalho 4, e exemplificadas na unidade anterior, são similares às colocadas no trabalho 10 o qual propõe que a seleção e organização dos conteúdos "estão relacionadas a uma temática a qual representa 
uma situação real que de alguma forma se faz presente no contexto dos alunos". Não obstante, o artigo 11 expõe que "a escolha cuidadosa de uma situação para se estudar, a SE, permite trabalhar temas relacionados ao cotidiano dos estudantes, fazendo com que os alunos passem a ter um pensamento químico sobre o mundo"; por isso mesmo, justificam que "A SE 'Água e Vida', além de ser do contexto de vivência dos estudantes, permite criar um contexto inter e transdisciplinar".

Já a unidade T9_2, apresentada anteriormente, está associada à premissa de que os estudantes auxiliam na definição do tema a ser abordado. Questões semelhantes foram identificadas no trabalho 17 , em que se observou "a turma do Ensino Médio em que seria realizada a implementação da SE e o perfil da turma foi definido. Em seguida solicitaram propostas de temas que a turma gostaria que fossem trabalhados" (T17_2). Neste caso, o tema desenvolvido foi "Produtos de limpeza". Todavia, no texto 20 , em que foram desenvolvidas três distintas temáticas, uma para cada série do ensino médio, as "temáticas foram escolhidas pelos alunos no componente curricular Seminário Integrado (SI), que tem a pesquisa como princípio pedagógico a ser desenvolvida e em articulação à temática geral da SE na área de conhecimento" (T20_1).

Com os resultados apresentados percebe-se que esta categoria carrega elementos associados, essencialmente, ao lócus da prática educativa. Diferentes são as justificativas que baseiam as escolhas, mas estas são definidas - após consultas, ou não, aos alunos - pelos sujeitos que organizam a ação, ou seja, pelos professores. A definição dos temas, por isso mesmo, ocorre de maneira mais intuitiva do que por meio de um processo investigativo, ou seja, a escolha parece estar baseada pela visão de algum(uns) dos sujeitos envolvidos, mas não existem métodos para a investigação deste contexto.

Assim como nos estudos apontados que se utilizam da perspectiva da SE, trabalhos que desenvolvem ações baseadas na AT Freireana (ATF) também preconizam a escolha dos temas baseados na realidade, ou dito de outra forma, em demandas da realidade.

A ATF é uma concepção curricular baseada na AT e, por isso mesmo, está associada à uma teoria curricular crítica. Ela é um caso específico de AT pois os modos de definição de escolha dos temas são singulares: almeja-se estruturar e desenvolver "temas geradores", os quais são particulares de cada comunidade/realidade investigada (FREIRE, 1987). Como já destacado, Muenchen et al. (2019) descrevem que os processos de busca podem ocorrer por três distintos vieses: pela investigação temática; por meio dos momentos pedagógicos; e pela práxis curricular via tema gerador.

Mesmo que o os modos de obtenção do Tema Gerador possam ser diferentes ${ }^{2}$ - pois em cada um existem etapas distintas, às atenções se voltam ao mesmo objeto de estudo, à realidade (contexto). Parte-se desta com o intuito de identificar as chamadas "situações-limite" (FREIRE, 1987), ou seja, as contradições das próprias interações entre sujeitos/sujeitos e sujeitos/realidade, para que, a partir da prática educativa, estas possam ser desveladas, problematizadas, trabalhadas, possibilitando a transformação daquela realidade.

De acordo com Magoga (2017), a produção e os desenvolvimentos 
vividos por determinadas comunidades. Ainda, segundo o autor, há uma importante relação entre a realidade e o conhecimento científico, pois a escolha deste depende daquela. Em outras palavras, a realidade é mediadora da ação educativa, de modo que, partindo dela, o processo educativo "deve ser organizado para que os sujeitos $1^{\circ}$ ) de posse dos conhecimentos científicos 2ㅇ) possam aprender e participar $3^{\circ}$ ) e, participando, possam problematizar e transformar as suas realidades" (MAGOGA, 2017, p.112).

As análises da categoria "Vivências cotidianas como balizadoras das escolhas" podem levar a pensar que os trabalhos aqui discutidos permutam relações com a ATF e, no limite, que a SE possui semelhanças com a AT. No entanto, as semelhanças ficam resguardadas ao destaque no uso do contexto, pois suas interpretações são distintas. Apesar de ambas considerarem um mesmo lócus, a realidade, a ATF possui modos de obtenção próprio, estando articulado à emersão do Tema Gerador (seja pela IT, 3MP e Momentos). Já na SE, com base nos artigos analisados, não se identificou métodos específicos de busca.

O desenvolvimento desta categoria, portanto, reitera a asserção proposta no trabalho de Magoga, Silva e Muenchen (2020): de que a SE é uma perspectiva curricular tal qual a AT, e não um tipo específico/modalidade de AT, como por exemplo a ATF. Esta constatação ampara-se no uso do contexto e de como este se relaciona com o conhecimento científico, pois ao se trabalhar com a realidade, na $\mathrm{SE}$, parte-se desta com o objetivo de desenvolver sucessivas significações conceituais; enquanto que na ATF, usa-se da realidade com o objetivo de transformá-la.

\section{DISTINTOS PARÂMETROS DE ESCOLHA}

O coletivo decidiu pelo tema "Aquecimento Global do Planeta" ou "Ar Atmosférico". Um dos critérios de escolha foi a amplitude com que o tema era discutido na mídia, com grande influência e impacto na vida dos estudantes, seja por meio da televisão, rádio, Internet, jornal, revistas de divulgação científica, etc (T13_1) (grifo nosso).

A categoria "Distintos parâmetros de escolha", representada pela unidade acima, contempla os trabalhos $7,8,13,14,15,16$. Nestes, as escolhas dos temas não enfocaram, de modo sistemático, apenas na valorização contextual, mas amparando-se nesta, justificaram a definição por meio de outros parâmetros. No trabalho 13, por exemplo, assim como nos trabalhos 7,16 e 18, os meios de comunicação, também chamados de mídia, influenciaram as ações desde a definição à estruturação.

A importância da mídia, articulada à dimensão contextual, e como esta determina o desenvolvimento das práticas educativas também pode ser identificada na unidade extraída do trabalho 7 , em que um dos assuntos que mais circulava na mídia e pela potencialidade de ser um contexto vivencial conceitualmente rico para as diversas ciências. Inúmeras fontes de pesquisa, recursos, estratégias e atividades de ensino passaram a fazer parte dos encontros de estudo e planejamento, em meio a inquietações, provocações, inseguranças, desafios e perspectivas que faziam parte desde 0 início da trajetória do processo coletivo em construção (T7_1). 
Justificativas das escolhas de temas baseados em assuntos discutidos na mídia são observados, também, em trabalhos que versam sobre outra perspectiva curricular, como a AT na perspectiva CTS. Auler (2007) e Auler, Dalmolin e Fenalti (2009), abordam tais aspectos e debatem sobre o fato de esta mídia também fazer parte do cotidiano escolar. Estudos mais recentes, como o de Lindenmaier et al. (2017) corroboram com as análises anteriores, e explicitam a necessidade de se problematizar as relações entre a ciência, a tecnologia e a sociedade pois

A escolha de temas pautada pelas mídias pode causar a sensação de uma boa escolha, no entanto, é questionável, primeiramente por que os meios de comunicação são empresas privadas e detêm interesses comerciais, de classes e defendem valores. Também, por que não significa que o que é notícia será importante para os estudantes. Ainda, sabe-se, que os meios de comunicação são ávidos por efemérides, deste modo, questões surgem e desaparecem rapidamente, e a não enunciação de tema/problema não significa que eles inexistam (LINDENMAIER, 2017, p.8).

Apesar dos trabalhos - baseados na SE - os quais compõem esta categoria assemelharem-se à estudos que utilizam a perspectiva da AT CTS, pois ambos justificam as escolhas temáticas por meio da mídia, destaca-se que, hegemonicamente, nestes últimos prevalecem as discussões de cunho político, pouco evidenciadas nos artigos do corpus. Obviamente, não se está a fazer certa imputação à uma ou outra concepção, mas explicitando que parecem haver elementos os quais diferem a perspectiva curricular da SE (ancorada, em primeira instância, às premissas historico-cultural de Vygostky) e a perspectiva curricular da AT (a qual, de modo mais veemente, objetiva elucidar as questões políticas entre a tríade).

Além do papel da mídia, outros elementos/características funcionaram como parâmetros para a definição dos temas, como por exemplo o contexto profissional, ou seja, articulada à formação do sujeito com o qual se destina a ação (trabalho 14); ou quando a SE foi pensada amparando-se nas proposições de documentos oficiais (trabalho 13). Não obstante, almeja-se destacar outro parâmetro relevante: a escolha do tema também esteve associado, em alguns casos, à uma adaptação conceitual, ou seja, para trabalhar/entender algum(ns) conceito(s) específico(s), como no caso dos artigos 8 e 15.

Foi a partir das discussões produzidas nesse grupo e as ações desenvolvidas nos estágios que Indiara interagiu com Estela, professora de química de uma escola pública estadual, negociou os conteúdos que deveria contemplar em sua proposta pedagógica e, a partir disso, produziu uma Situação de Estudo (T8_1) (grifo nosso).

Neste sentido, inicialmente tínhamos o desafio de contemplar os conteúdos de Biologia do 2ㅇ Ano do Ensino Médio. O conteúdo proposto pela escola era Anatomia e Fisiologia Humana. A etapa de elaboração coletiva favoreceu a apropriação de conhecimentos específicos dos conteúdos que seriam desenvolvidos em sala de aula. Na interação com professores de Física, Biologia e Química da escola, ocorreu a compreensão dos conceitos sob um outro olhar (T15_2) (grifo nosso).

Apesar de perceber que o fato da adequação conceitual interfere na definição dos temas, em ambos a necessidade de adequação à determinados conteúdos (referentes aos conhecimentos científicos) pode ser entendida como uma 
imposição, alheia às vontades dos sujeitos coordenadores da ação. Tal fato também ocorre em alguns trabalhos baseados na perspectiva da AT e na visão de Auler, Dalmolin e Fenalti (2009), a ressignificação curricular, em alguns destes casos, perpassa pela contextualização de determinados conceitos, isto é, altera-se a "roupagem conceitual" de modo que a construção curricular pode ficar fragilizada.

De modo geral, portanto, a presente categoria contém trabalhos os quais mostram que a definição dos temas estão associados à distintos parâmetros, mas que estes são próximos às justificativas apresentadas por alguns trabalhos baseados na perspectiva da AT CTS.

Soma-se às discussões apresentadas o fato de que em ambas as abordagens curriculares - SE e AT -, por exemplo, na maioria dos casos é o professor quem define/escolhe a temática a ser desenvolvida. Além disso, as temáticas de cunho CTS são caracterizadas por Auler (2007) como sendo mais abrangentes, gerais, não se restringindo a um contexto específico; tal ocorrência também é percebida nos trabalhos desta categoria, pois os temas são "Aquecimento global do Planeta", "Os medicamentos e as dores dos seres humanos: síntese e ação dos fármacos"; "Automedicação: um mal necessário?"; "Alimentos como forma de manutenção da vida" e "Alisantes - uma forma de ensinar concentração". Por serem mais gerais, podem ser desenvolvidos/aplicáveis a distintos contextos, diferindo, dessa maneira, dos temas identificados na categoria anterior.

\section{ALGUMAS CONSIDERAÇÕES}

Uma das premissas que balizou este trabalho é a de que, na área de educação em Ciências, existem distintos modos de conceber e executar currículos escolares; modos os quais - mesmo comungando do uso de temas - possuem raízes e são disseminadas de formas singulares. À exemplo disto, colocam-se a Situação de Estudo e a Abordagem Temática, perspectivas curriculares paralelas, mas que muitas vezes são entendidas, apenas, como hierarquicamente distintas, isto é, uma como modalidade da outra.

A fim romper com tal concepção e de tecer provocações sobre tais aspectos, elaborou-se o presente estudo o qual defende que as perspectivas de reorganização dos currículos escolares balizadas por temas são orgânicas, uma vez que, possuem distinções pedagógicas e epistemológicas, mas como elemento central buscam a superação de currículos que não estejam em sintonia com o contexto dos sujeitos envolvidos no processo de ensino aprendizagem.

Entretanto, as interpretações sobre o contexto e as relações entre este, os sujeitos e o conhecimento científico, podem estar associados a estas distintas concepções curriculares. As compreensões de tais relações podem refletir, por exemplo, na participação dos sujeitos nas escolhas dos temas (desde um nível "consultivo" à um nível de envolvimento mais prático, por parte dos sujeitos), ou nas formas contexto-conceito ou conceito-contexto.

Amparando-se nas análises realizadas, envolvendo especificamente a escolha dos temas, identifica-se que na SE o contexto é percebido como o cotidiano vivencial, o qual pode ser entendido a partir dos conhecimentos científicos. Esta concepção de contexto difere-se da perspectiva freireana, ou mais 
especificamente da ATF, quando este é entendido como realidade, a ser desvelada e transformada.

Não obstante, vislumbra-se que modalidades baseadas na AT, como a ATF e Freire-CTS, possuem amplas discussões na literatura em Ensino de Ciências sobre os processos de obtenção do Tema Gerador, o qual é de natureza contextual. Porém, percebe-se que a modalidade Educação CTS e a perspectiva SE possuem características dinâmicas em "critérios" de escolha dos temas, variando entre o contextual e conceitual, ou seja, em termos da tríade utilizada neste estudo, perpassando o contexto e o conhecimento científico.

Ao final destas discussões, portanto, reafirmam-se as interpretações e singularidades dos papéis entre os sujeitos-contextos-conhecimentos científicos nos processos de escolha dos temas. Reitera-se que não se atribui "valor" para cada um dos elementos da tríade no processo de obtenção do tema, mas se destacam as particularidades no interior das perspectivas aqui discutidas em interpretar tais elementos. Argumenta-se, com isso, sobre as possíveis diferenças entre a perspectiva da SE e da $\mathrm{AT}$, as quais não minimizam uma ou outra, mas que as caracterizam como próprias. 


\title{
Study situation and thematic approach: analysis on theme choices
}

\begin{abstract}
This study discusses the processes for choosing themes in the context of the perspectives of curricular reorganization of the Thematic Approach and the Study Situation, through a bibliographic review in works published in the minutes of the Encontro Nacional de Pesquisas em Educação em Ciências (ENPEC), from 1997 to 2017. Thus, this work is concerned with answering the following question: How have the themes been defined in educational practices based on the Study Situation, in comparison to the Thematic Approach? Methodologically of a qualitative nature, the analysis of the selected works was guided by the assumptions of the Discursive Textual Analysis, thus emerging two analytical categories (i) Daily experiences as beacons of choices and ii) Different parameters of choices. This signals the apparent distinction in the interpretations of the elements of the subject - context - scientific knowledge triad to choices and approach the themes in the context of the curricular perspectives Situation of Study and Thematic Approach.
\end{abstract}

KEYWORDS: Choice of Themes. Curricular Perspectives Study Situation. Thematic Approach. Educational Practices. 


\section{NOTAS}

${ }^{1}$ Sinaliza-se que a análise dos trabalhos foi realizada anteriormente a publicação das atas da décima segunda edição do ENPEC.

${ }^{2}$ Não é o foco abordar, neste artigo, as diferenças dos três modos entre si, mas do conjunto, as quais são $\mathrm{ATF}$, em relação à perspectiva da SE.

\section{REFERÊNCIAS}

AULER, D.; DALMOLIN, A.M.T. e FENALTI, V.S. Abordagem Temática: natureza dos temas em Freire e no enfoque CTS. Alexandria - Revista de Educação em Ciência e Tecnologia, v.2, n.1, p.67-84, mar. 2009.

AULER, D. Enfoque ciência-tecnologia-sociedade: pressupostos para o contexto Brasileiro. Ciência \& Ensino, vol. 1, número especial, novembro de 2007.

AULER, D. Interações entre Ciência-Tecnologia- Sociedade no contexto de formação de professores de Ciências. 2002. 257 p. Tese - Universidade Federal de Santa Catarina, Florianópolis, 2002.

BRASIL. Base Nacional Comum Curricular: Ensino Médio. Brasília: MEC/Secretaria de Educação Básica, 2018.

DELIZOICOV, D. Conhecimento, Tensões e Transições. Tese de Doutorado. São Paulo: FEUSP, 1991.

DELIZOICOV, D.; ANGOTTI, J; PERNAMBUCO, M. Ensino de ciências: fundamentos e métodos. São Paulo: Cortez, 2011.

FREIRE, P. Pedagogia do Oprimido. Rio de Janeiro: Paz e Terra, 1987.

GIL, A. C. Como elaborar projetos de pesquisa. 5. ed. São Paulo: Atlas, 2010.

HALMENSCHLAGER, K. R. Abordagem de temas em ciências da natureza no ensino médio: implicações na prática e na formação docente. 373 p. Tese (Doutorado em Educação Científica e Tecnológica) - Universidade Federal de Santa Catarina, Florianópolis/SC, 2014.

HUNSCHE, S. Professor "fazedor" de currículos: desafios no estágio curricular supervisionado em ensino de física. 2010. 143 p. Dissertação (Mestrado em Educação) - Universidade Federal de Santa Maria, Santa Maria, 2010.

KLEIN, S. G. et al. Abordagem Temática na educação básica: um olhar para as diferentes modalidades nas aulas de ciências da natureza. Ciências \& Ideias (no prelo).

LINDENMAIER, D. et al. A definição do tema no enfoque CTS: uma visão a partir de trabalhos do X ENPEC. In: XI Encontro Nacional de Pesquisa em Educação em Ciências - Atas, Florianópolis, 2017. 
MAGOGA, T. F. Abordagem Temática na educação em ciências: um olhar à luz da epistemologia fleckiana. Dissertação de Mestrado. Santa Maria, RS: UFSM, 2017.

MAGOGA, T. F.; SILVA, J. M.; MUENCHEN, C. Situação de Estudo e Abordagem Temática: Relações, Discussões e Sinalizações Contexto \& Educação, v. 35, n.111, p. 127-147, 2020.

MALDANER, O. A. Situações de Estudo no Ensino Médio: Nova Compreensão de Educação Básica. In: Roberto Nardi. (Org.). A Pesquisa Em Ensino de Ciências no Brasil: alguns recortes. 1eed.São Paulo: Escrituras, 2007, v. único, p. 241-256.

MARQUES, S. G. et al. A Inserção da Abordagem Temática na Educação Básica: um olhar sobre o currículo. Currículo sem Fronteiras (no prelo).

MORAES. R.; GALIAZZI, M. C. Análise textual discursiva. Ijuí: Editora Unijuí, 2007.

MUENCHEN, C. A disseminação dos três momentos pedagógicos: um estudo sobre as práticas docentes na região de Santa Maria/RS. Tese de Doutorado. Universidade Federal de Santa Catarina, Florianópolis, 2010.

MUENCHEN, C; et al. Os três momentos pedagógicos na formação inicial de professores: o trabalho com temas geradores. In: WATANABE, G. (org). Educação Científica Freireana na Escola, São Paulo: Editora Livraria da Física, 2019.

SILVA, A. F. G. Das falas significativas às práticas contextualizadas: a construção do currículo na perspectiva crítica e popular. Tese (doutorado), São Paulo: PUC, 2004.

STRIEDER, R. B. Abordagem CTS a Educação Científica no Brasil: Sentidos e Perspectivas. Tese de Doutorado. Universidade de São Paulo, São Paulo, 2012.

VIEIRA, L; B. G. Situação de Estudo: compreensões dos formadores de professores do ensino de ciências. 2017. 121 p. Dissertação (de Mestrado em Educação em Ciências) Programa de Pós-Graduação em Educação em Ciências, Universidade Estadual de Santa Cruz, Ilhéus, 2017.

Recebido: 03 abr. 2020

Aprovado: 31 mai. 2020

DOI: $10.3895 /$ actio.v5n2.11907

Como citar:

SILVA, J. M. da.; MAGOGA, T. F.; MUENCHEN, C. Situação de estudo e abordagem temática: análises sobre as escolhas dos temas. ACTIO, Curitiba, v. 5, n. 2, p. 1-18, mai./ago. 2020. Disponível em:

$<$ https://periodicos.utfpr.edu.br/actio>. Acesso em: XXX

Correspondência:

Josiane Marques da Silva

Rua Vergílio Paz, n. 225, São Domingos, Caçapava do Sul, Rio Grande do Sul, Brasil.

Direito autoral: Este artigo está licenciado sob os termos da Licença Creative Commons-Atribuição 4.0

Internacional.

(c) (i) 